Universität des Saarlandes University of Saarland

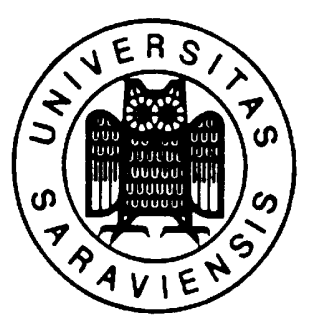

Volkswirtschaftliche Reihe

Economic Series

\title{
Hedging With Mismatched CuRREnCIES
}

\section{Udo Broll and Kit Pong Wong}

Economic Series No. 9910

June 1999

\section{University of Saarland}

Department of Economics (FB 2)

$$
\text { P.O. Box } 151150
$$

D-66041 SAARBRUECKEN, GERMANY

Phone: +49-681-302 -4353, Fax:-4390

http://www.iwb.uni-sb.de

E-mail: broll@iwb.uni-sb.de

University of Hong Kong

School of Economics and Finance

Pokfulam Road

HONG KONG

Phone: +852-2859-1044, Fax:-2548-1152

E-mail: kpwong@econ.hku.hk 


\begin{abstract}
This paper presents a model of a risk-averse multinational firm facing risk exposure to a foreign currency cash flow. Forward markets do not exist between the firm's own currency and the foreign currency, but do exist for a third currency. Since a triangular parity condition holds among these three currencies, the available forward markets, albeit incomplete, provide a useful avenue for the firm to indirectly hedge against its foreign exchange rate risk exposure. This paper offers analytical insights into the optimal cross-hedging strategies of the firm. In particular, the results show that separate unbiasedness of the forward markets does not necessarily imply a perfect full hedge which eliminates the entire foreign exchange rate risk exposure of the firm. The optimal cross-hedging strategies depend largely on the firm's marginal utility function and on the correlation of the random spot exchange rates.
\end{abstract}

JEL Codes: F21; F31

Keywords: Multiple exchange rate risks; Currency forward markets; Cross-hedging

We would like to thank Ron Anderson and an anonymous referee for helpful comments. The usual disclaimer applies. 


\section{INTRODUCTION}

Since the collapse of the Bretton Woods system of fixed exchange rates, foreign exchange rates have become substantially volatile [see Meese (1990)]. In response to increased exchange rate fluctuations, corporations which source and sell abroad have to devote themselves to devising ways for reduction of foreign exchange rate risk exposures. This is evident from a survey conducted by Rawls and Smithson (1990) that exchange rate risk management is ranked as one of the primary corporate objectives.

Given the real-world prominence of exchange rate risk management, there have been numerous contributions to the theory of multinational firms facing foreign exchange rate risk exposures in which the effects and the role of currency forward markets are thoroughly analyzed [see, e.g., Katz and Paroush (1979), Benninga, Eldor, and Zilcha, (1985), Kawai and Zilcha (1986), and Froot, Scharfstein, and Stein (1993)]. One important result emanating from these studies is the celebrated 'fullhedging theorem' which states that a risk-averse multinational firm should fully hedge against its risk exposure to a foreign currency cash flow when an unbiased forward market between its own currency and the foreign currency exists. Given complete financial markets, a perfect full hedge which eliminates all foreign exchange rate risk exposures is always a possible choice confronted by multinational firms.

In the real world, financial markets are far from complete and not all currencies have forward markets. This is especially prominent in less developed countries (LDCs) where capital markets are embryonic and foreign exchange markets are highly controlled. Even if currency forward contracts are available in some LDCs, they deem to be forward-cover insurance schemes rather than financial instruments whose prices are freely determined by market forces [see Jacque (1996)]. Also, in many of the newly industrializing countries of Latin America and Asia-Pacific, forward markets 
for these so-called 'exotic currencies' are just starting to develop at a slow pace [see Eiteman, Stonehill, and Moffett (1998)]. Multinational firms which expose to currencies of these countries thus have to rely on forward contracts on related currencies to indirectly hedge against their foreign exchange rate risk exposures. Such an exchange rate risk management technique is referred to as 'cross-hedging' [see, e.g., Anderson and Danthine (1981), Powers and Castellino (1991), and Sercu and Uppal (1995)].

The purpose of this paper is to provide theoretical insights into the optimal crosshedging strategies of multinational firms. To this end, the paper presents a model of a risk-averse multinational firm expecting a net cash flow from its operation domiciled in a foreign country. Currency forward markets between the firm's home country and the foreign country do not exist. There is, however, a third country which has welldeveloped currency forward markets to which the firm has access. A triangular parity condition holds among the currencies of these three countries so that $\tilde{S}_{02}=\tilde{S}_{01} \tilde{S}_{12}$, where $\tilde{S}_{i j}$ is the random spot exchange rate of country $i$ 's currency against country $j$ 's currency, and the home, third, and foreign countries are indexed by 0,1 , and 2, respectively. Consistent with the empirical findings of Eaker and Grant (1987), cross-hedging provided by the available, yet incomplete, currency forward markets is useful to the firm in reducing its foreign exchange rate risk exposure.

In this paper, two different scenarios of cross-hedging are considered. In the first scenario, referred to as the case of imperfect cross-hedging, the multinational firm has access to the currency forward market between the third and foreign countries but not to the one between the home and third countries. When the currency forward market between the third and foreign countries is unbiased, a full hedge is optimal should $\tilde{S}_{01}$ and $\tilde{S}_{12}$ be stochastically independent. The firm's domestic currency income, however, remains uncertain, at odds with the full-hedging theorem. The 
randomness of the firm's domestic currency income is due entirely to the missing currency forward market between the home and third countries. In the case where $\tilde{S}_{01}$ and $\tilde{S}_{12}$ are correlated, a portfolio of currencies creates a 'natural hedge' against each other through diversification effects, thereby inducing the firm to deviate from a full hedge against its foreign exchange rate risk exposure.

In the second scenario, referred to as the case of perfect cross-hedging, the multinational firm has access to the currency forward market between the third and foreign countries as well as the one between the home and third countries. In this case, the firm always uses these two currency forward markets jointly so as to synthesize a forward contract for $\tilde{S}_{02}$, for which risk-sharing markets are missing. Contracting in only one currency forward market will necessarily result in an open position for at least one currency, which is not optimal should these two currency forward markets be separately unbiased. Although a double full hedge which eliminates the entire foreign exchange rate risk exposure is always a possible choice within the firm's own discretion, such a cross-hedging strategy is optimal only when $\tilde{S}_{01}$ and $\widetilde{S}_{12}$ are stochastically independent. In the general case where these two random spot exchange rates are correlated, the optimal cross-hedging strategy is never a double full hedge and depends largely on the firm's marginal utility function and on the correlation of the random spot exchange rates.

The rest of the paper is organized as follows. The next section delineates a model of a risk-averse multinational firm facing exchange rate uncertainty and cross-hedging opportunities. The third section characterizes the optimal imperfect cross-hedge of the firm when only one currency forward market is present. The fourth section introduces one more currency forward market which reduces the incompleteness of financial markets. The optimal perfect cross-hedge of the firm is then characterized 
and contrasted with the optimal imperfect cross-hedge. The final section concludes.

\section{THE MODEL}

Consider a multinational firm with an operation domiciled in a foreign country. There are no currency forward markets between the firm's home country and the foreign country. There is, however, a third country with well-developed currency forward markets to which the firm has access. The home, third, and foreign countries are indexed by 0,1 , and 2 , respectively. Define $\tilde{S}_{i j}$ as the spot exchange rate expressed in units of country $i$ 's currency per unit of country $j$ 's currency, where a tilde $(\sim)$ always signifies a random variable and $\tilde{S}_{i j}$ is non-negative and not known ex ante to the firm. Likewise, define $F_{i j}$ as the forward exchange rate expressed in units of country $i$ 's currency per unit of country $j$ 's currency, which is pre-determined in the currency forward market between countries $i$ and $j$. Figure 1 depicts the structure of the currency spot and forward markets.

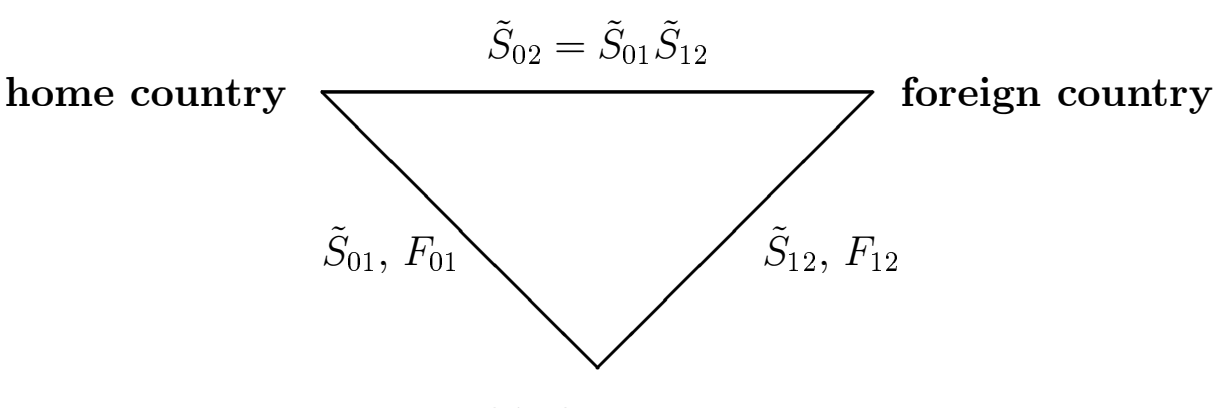

third country

\section{FIGURE 1}

Currency spot and forward markets.

Based on the spot exchange rates, $\tilde{S}_{01}$ and $\tilde{S}_{12}$, one can derive a cross-rate of the 
domestic currency against the foreign currency as $\tilde{S}_{01} \tilde{S}_{12}$. By the Law of One Price, it must be true that $\tilde{S}_{02}=\tilde{S}_{01} \tilde{S}_{12}$. Furthermore, one can consider a linear projection of $\tilde{S}_{12}$ on $\tilde{S}_{01}$, which is always possible, to yield $\tilde{S}_{12}=\alpha+\beta \tilde{S}_{01}+\tilde{\epsilon}$, where $\alpha$ and $\beta$ are constants with $\alpha>0$, and $\tilde{\epsilon}$ is a zero-mean, finite-variance, random variable independent of $\tilde{S}_{01}$. If $\beta$ is positive (negative), $\tilde{S}_{01}$ and $\tilde{S}_{12}$ are positively (negatively) correlated. These two random variables are independent only when $\beta=0$.

The firm expects to receive a net cash flow from its foreign operation, $X$, denominated in the foreign currency. Since the firm cannot accurately forecast the spot exchange rate of the domestic currency against the foreign currency, $\tilde{S}_{02}$, it inevitably encounters a foreign exchange rate risk exposure of $\tilde{S}_{02} X$. To indirectly hedge against this risk exposure, the firm can make use of the currency forward markets in the third country. Let $H_{i j}$ be the units of country $j$ 's currency sold (purchased if negative) forward in the currency forward market between countries $i$ and $j$. The firm's income denominated in the domestic currency is given by

$$
\tilde{W}=\tilde{S}_{02} X+\left(F_{01}-\tilde{S}_{01}\right) H_{01}+\tilde{S}_{01}\left(F_{12}-\tilde{S}_{12}\right) H_{12}
$$

where $\left(F_{01}-\tilde{S}_{01}\right) H_{01}$ is the net gain or loss, denominated in the domestic currency, due to the firm's position in the currency forward market between the home and third countries, and $\left(F_{12}-\tilde{S}_{12}\right) H_{12}$ is the net gain or loss, denominated in the third currency, due to the firm's position in the currency forward market between the third and foreign countries.

The firm is risk averse and possesses a von Neumann-Morgenstern utility function, $U$, defined over its domestic currency income, with $U^{\prime}>0$ and $U^{\prime \prime}<0$. The firm is an expected utility maximizer and has to solve the following decision problem:

$$
\max _{H_{01}, H_{12}} \mathrm{E}[U(\tilde{W})]
$$


where $\mathrm{E}$ is the expectation operator and $\tilde{W}$ is defined in eq. (??).

\section{OPTIMAL IMPERFECT CROSS-HEDGING}

This section examines the case of imperfect cross-hedging in which only the currency forward market between the third and foreign countries is accessible by the multinational firm. Using eq. (??) and the fact that $\tilde{S}_{02}=\tilde{S}_{01} \tilde{S}_{12}$ and $H_{01}=0$, the firm's income denominated in the domestic currency becomes

$$
\tilde{W}=\tilde{S}_{01} F_{12} X+\tilde{S}_{01}\left(F_{12}-\tilde{S}_{12}\right)\left(H_{12}-X\right)
$$

The first-order condition for the optimization problem, eq. (??), with $\tilde{W}$ being defined in eq. (??), is given by

$$
\mathrm{E}\left[U^{\prime}\left(\tilde{W}^{*}\right) \tilde{S}_{01}\left(F_{12}-\tilde{S}_{12}\right)\right]=0
$$

where an asterisk $\left(^{*}\right)$ indicates an optimal level. Using the covariance operator, Cov, eq. (??) can be written as

$$
\mathrm{E}\left[U^{\prime}\left(\tilde{W}^{*}\right) \tilde{S}_{01}\right]\left[F_{12}-\mathrm{E}\left(\tilde{S}_{12}\right)\right]-\operatorname{Cov}\left[U^{\prime}\left(\tilde{W}^{*}\right) \tilde{S}_{01}, \tilde{S}_{12}\right]=0
$$

The second-order condition satisfies trivially given risk aversion.

The optimal imperfect cross-hedge is an over hedge, a full hedge, or an under hedge, depending on whether $H_{12}^{*}$ is greater than, equal to, or less than $X$, respectively. The currency forward market between the third and foreign countries is said to be unbiased if, and only if, $F_{12}=\mathrm{E}\left(\tilde{S}_{12}\right)$. It follows from eq. (??) and the unbiasedness of the currency forward market between the third and foreign countries that eq. (??) reduces to

$$
\operatorname{Cov}\left\{U^{\prime}\left[\tilde{S}_{01} F_{12} X+\tilde{S}_{01}\left(F_{12}-\tilde{S}_{12}\right)\left(H_{12}^{*}-X\right)\right] \tilde{S}_{01}, \tilde{S}_{12}\right\}=0
$$


If $\beta=0$ so that $\tilde{S}_{01}$ and $\tilde{S}_{12}$ are independent, inspection of eq. (??) reveals that $H_{12}^{*}=X$, thereby invoking the following proposition [see also Broll, Wong, and Zilcha (1998) for a slightly more general result].

Proposition 1. Suppose that the currency forward market between the third and foreign countries is unbiased and that $\tilde{S}_{01}$ and $\tilde{S}_{12}$ are independent. It is optimal for the multinational firm to fully hedge against its foreign exchange rate risk exposure.

To see the intuition underlying Proposition 1, note that

$$
\mathrm{E}\left(\tilde{S}_{02}\right)=\mathrm{E}\left(\tilde{S}_{01} \tilde{S}_{12}\right)=\mathrm{E}\left(\tilde{S}_{01}\right) \mathrm{E}\left(\tilde{S}_{12}\right)=\mathrm{E}\left(\tilde{S}_{01}\right) F_{12}
$$

where the second equality follows from the independence of $\widetilde{S}_{01}$ and $\tilde{S}_{12}$, and the third equality follows from the unbiasedness of the currency forward market between the third and foreign countries. According to Bohenstedt and Goldberger (1969) [see also Kerkvliet and Moffett (1991), and Broll, Wong, and Zilcha (1998)],

$$
\begin{aligned}
\operatorname{Var}\left(\tilde{S}_{02}\right) & =\operatorname{Var}\left(\tilde{S}_{01} \tilde{S}_{12}\right) \\
& =\mathrm{E}\left(\tilde{S}_{01}\right)^{2} \operatorname{Var}\left(\tilde{S}_{12}\right)+\operatorname{Var}\left(\tilde{S}_{01}\right) \mathrm{E}\left(\tilde{S}_{12}\right)^{2}+\operatorname{Var}\left(\tilde{S}_{01}\right) \operatorname{Var}\left(\tilde{S}_{12}\right) \\
& >\operatorname{Var}\left(\tilde{S}_{01}\right) F_{12}^{2}
\end{aligned}
$$

where the second equality follows from the independence of $\tilde{S}_{01}$ and $\tilde{S}_{12}$, and the inequality follows from the fact that $F_{12}=\mathrm{E}\left(\tilde{S}_{12}\right)$ and $\tilde{S}_{01}$ and $\tilde{S}_{12}$ are non-degenerate, non-negative, random variables. It is evident from eq. (??) and eq. (??) that $\tilde{S}_{02}$ is dominated by $\tilde{S}_{01} F_{12}$ in that the former has the same mean but higher variance than the latter. Consequently, it is optimal for the risk-averse firm to fully hedge against its foreign exchange rate risk exposure so as to drive down the underlying risk from $\tilde{S}_{02}$ to $\tilde{S}_{01} F_{12}$. 
It follows from Proposition 1 and eq. (??) that the firm's domestic currency income under a full hedge (i.e., $\left.H_{12}^{*}=X\right)$ is given by

$$
\tilde{W}^{*}=\tilde{S}_{01} F_{12} X
$$

which remains stochastic. This is at odds with the celebrated full-hedging theorem which implies non-random profits for firms having access to unbiased forward markets [see, e.g., Katz and Paroush (1979), Benninga, Eldor, and Zilcha (1985), Kawai and Zilcha (1986), and Froot, Scharfstein, and Stein (1993)]. Inspection of eq. (??) reveals that the randomness of the firm's domestic currency income is attributable entirely to the random spot exchange rate, $\tilde{S}_{01}$, which is not hedgeable due to the missing currency forward market between the home and third countries.

In the general case where $\beta \neq 0$, the notion of relative risk aversion of Arrow (1965) and Pratt (1964) will soon prove to play a pivotal role in determining the optimal imperfect cross-hedge. This is not surprising because absolute risk aversion usually applies to additive risks while relative risk aversion usually applies to multiplicative risks [see, e.g., Eeckhoudt and Gollier (1995), and Chow and Wong (1998)]. The ArrowPratt measure of relative risk aversion is defined as $R(W)=-W U^{\prime \prime}(W) / U^{\prime}(W)$, for any given domestic currency income level of the firm, $W$.

The following proposition deals with the case where $\tilde{S}_{01}$ and $\tilde{S}_{12}$ are negatively correlated. The case of positive correlation of $\tilde{S}_{01}$ and $\tilde{S}_{12}$ will be deferred for the time being.

Proposition 2. Suppose that the currency forward market between the third and foreign countries is unbiased and that $\tilde{S}_{01}$ and $\tilde{S}_{12}$ are negatively correlated. It is optimal for the multinational firm to adopt an over hedge, a full hedge, or an under hedge against its foreign exchange rate risk exposure, depending on whether its Arrow- 
Pratt measure of relative risk aversion is everywhere less than, equal to, or greater than unity, respectively.

Proof. See the appendix.

The intuition of Proposition 2 is as follows. Taking expectation on both sides of eq. (??) yields

$$
\mathrm{E}(\tilde{W})=\mathrm{E}\left(\tilde{S}_{01} \tilde{S}_{12}\right) X+\left[\mathrm{E}\left(\tilde{S}_{01}\right) F_{12}-\mathrm{E}\left(\tilde{S}_{01} \tilde{S}_{12}\right)\right] H_{12}
$$

Note that

$$
\mathrm{E}\left(\tilde{S}_{01} \tilde{S}_{12}\right)=\mathrm{E}\left(\tilde{S}_{01}\right) \mathrm{E}\left(\tilde{S}_{12}\right)+\operatorname{Cov}\left(\tilde{S}_{01}, \tilde{S}_{12}\right)=\mathrm{E}\left(\tilde{S}_{01}\right) F_{12}+\beta \operatorname{Var}\left(\tilde{S}_{01}\right)
$$

where the second equality follows from the unbiasedness of the currency forward market between the third and foreign countries and the linear projection of $\tilde{S}_{12}$ on $\tilde{S}_{01}$. For $\beta<0$, inspection of eq. (??) reveals that $\mathrm{E}\left(\tilde{S}_{01} \tilde{S}_{12}\right)<\mathrm{E}\left(\tilde{S}_{01}\right) F_{12}$. Thus, eq. (??) implies that $\mathrm{E}(\tilde{W})$ is strictly increasing in $H_{12}$. In other words, the currency forward market between the third and foreign countries, albeit unbiased, bestows upon the firm a speculative incentive to sell the foreign currency forward.

Taking variance on both sides of eq. (??) yields

$$
\begin{aligned}
\operatorname{Var}(\tilde{W})= & F_{12}^{2} H_{12}^{2} \operatorname{Var}\left(\tilde{S}_{01}\right)+\left(X-H_{12}\right)^{2} \operatorname{Var}\left(\tilde{S}_{01} \tilde{S}_{12}\right) \\
& +2 F_{12} H_{12}\left(X-H_{12}\right) \operatorname{Cov}\left(\tilde{S}_{01}, \tilde{S}_{01} \tilde{S}_{12}\right)
\end{aligned}
$$

Partially differentiating eq. (??) with respect to $H_{12}$ and evaluating at $H_{12}=X$ yields

$$
\left.\frac{\partial \operatorname{Var}(\tilde{W})}{\partial H_{12}}\right|_{H_{12}=X}=2 F_{12} X\left[F_{12} \operatorname{Var}\left(\tilde{S}_{01}\right)-\operatorname{Cov}\left(\tilde{S}_{01}, \tilde{S}_{01} \tilde{S}_{12}\right)\right]
$$


Following Bohenstedt and Goldberger (1969) [see also Kerkvliet and Moffett (1991)],

$$
\operatorname{Cov}\left(\tilde{S}_{01}, \tilde{S}_{01} \tilde{S}_{12}\right)=\mathrm{E}\left(\tilde{S}_{12}\right) \operatorname{Var}\left(\tilde{S}_{01}\right)+\beta \mathrm{E}\left\{\left[\tilde{S}_{01}-\mathrm{E}\left(\tilde{S}_{01}\right)\right]^{2} \tilde{S}_{01} \tilde{S}_{12}\right\}
$$

given the linear projection of $\tilde{S}_{12}$ on $\tilde{S}_{01}$. Using eq. (??) and the unbiasedness of the currency forward market between the third and foreign countries, eq. (??) reduces to

$$
\left.\frac{\partial \operatorname{Var}(\tilde{W})}{\partial H_{12}}\right|_{H_{12}=X}=-2 F_{12} X \beta \mathrm{E}\left\{\left[\tilde{S}_{01}-\mathrm{E}\left(\tilde{S}_{01}\right)\right]^{2} \tilde{S}_{01} \tilde{S}_{12}\right\},
$$

which is positive for $\beta<0$. When $\tilde{S}_{01}$ and $\tilde{S}_{12}$ are negatively correlated, it pays the firm to bear some risk associated with $\tilde{S}_{12}$. A portfolio of currencies is 'naturally' hedged as movements in spot exchange rates offset each other through diversification effects. Alternatively put, a portfolio with both currencies has lower risk than either spot exchange rate. This induces the firm to under hedge against its foreign exchange rate risk exposure so as to reduce the volatility of its domestic currency income. This risk minimization incentive dominates, or is dominated by, the speculative incentive, depending on whether the firm is sufficiently risk averse or not, respectively.

Now, consider the case where $\tilde{S}_{01}$ and $\tilde{S}_{12}$ are positively correlated. The proof of the following proposition is analogous to that of Proposition 2 and thus is omitted.

Proposition 3. Suppose that the currency forward market between the third and foreign countries is unbiased and that $\tilde{S}_{01}$ and $\tilde{S}_{12}$ are positively correlated. It is optimal for the multinational firm to adopt an under hedge, a full hedge, or an over hedge against its foreign exchange rate risk exposure, depending on whether its ArrowPratt measure of relative risk aversion is everywhere less than, equal to, or greater than unity, respectively.

It follows from eq. (??) and $\beta>0$ that $\mathrm{E}\left(\tilde{S}_{01} \tilde{S}_{12}\right)>\mathrm{E}\left(\tilde{S}_{01}\right) F_{12}$. Eq. (??) then implies that $\mathrm{E}(\tilde{W})$ is strictly decreasing in $H_{12}$, thereby giving the firm a speculative 
incentive to purchase the foreign currency forward. However, according to eq. (??) and $\beta>0$, the firm should over hedge against its foreign exchange rate risk exposure so as to reduce the volatility of its domestic currency income. This risk minimization incentive dominates, or is dominated by, the speculative incentive, depending on whether the firm is sufficiently risk averse or not, respectively.

The result that a full hedge is not optimal even in unbiased forward/futures markets is well known in the hedging literature, where it is common knowledge that the minimum-variance hedge ratio equals $\operatorname{Cov}(\tilde{S}, \tilde{F}) / \operatorname{Var}(\tilde{F})$ and thus depends on how the spot price, $\tilde{S}$, is correlated with the forward/futures price, $\tilde{F}$. Especially with futures markets, it is likely the case that $\tilde{S}$ and $\tilde{F}$ are not perfectly correlated because of maturity mismatches or problems with the underlying assets as in commodity futures. While in this regard the basic problem of hedging with mismatched currencies is not new, the results of this paper do contribute additional insights beyond the extant literature. Even under quadratic utility functions so that the mean-variance analysis applies, Propositions 2 and 3 imply that preference parameters remain an important determinant of the optimal hedge ratio. This implication differs from that of the mean-variance hedge ratio because the source of exchange rate uncertainty specified in this paper is multiplicative in nature, rather than additive as commonly found in most hedging models.

Before leaving this section, it is of interest to conduct a numerical analysis so as to give more practical/empirical contents.

An Example. Suppose that the firm has a power utility function, $U(W)=$ $(W / \gamma)^{1-\gamma} \gamma /(1-\gamma)$, where $\gamma$ is the constant Arrow-Pratt measure of relative risk aversion and $0<\gamma<1$. $\tilde{S}_{01}$ takes on 1 or 2 with equal probabilities so that its expected value is 1.5. The linear projection of $\tilde{S}_{12}$ on $\tilde{S}_{01}$ is given by $\tilde{S}_{12}=1+$ 
$\beta\left(\tilde{S}_{01}-1.5\right)+\sigma \tilde{\epsilon}$, where $\sigma$ is a positive constant and $\tilde{\epsilon}$ takes on -0.5 or 0.5 with equal probabilities. It follows from the unbiasedness of the currency forward market between the third and foreign countries that $F_{12}=1$. Table 1 tabulates optimal hedge ratios for different correlation structures, $\beta$, different levels of the bias, $\sigma$, and different Arrow-Pratt measures of relative risk aversion, $\gamma$.

\section{TABLE 1}

Optimal Hedge Ratios

\begin{tabular}{ccccccc}
\hline \multicolumn{2}{c}{ Parameters } & \multicolumn{5}{c}{$\beta$} \\
$\sigma$ & $\gamma$ & -1 & -0.5 & 0 & 0.5 & 1 \\
\hline 0.1 & 0.5 & 2.684 & 4.112 & 1 & -2.112 & -0.684 \\
0.2 & 0.5 & 2.556 & 3.657 & 1 & -1.657 & -0.556 \\
0.3 & 0.5 & 2.436 & 3.296 & 1 & -1.296 & -0.436 \\
0.4 & 0.5 & 2.328 & 3.006 & 1 & -1.006 & -0.328 \\
0.5 & 0.5 & 2.233 & 2.765 & 1 & -0.765 & -0.233 \\
0.5 & 0.6 & 2.166 & 2.639 & 1 & -0.639 & -0.166 \\
0.5 & 0.7 & 2.095 & 2.515 & 1 & -0.515 & -0.095 \\
0.5 & 0.8 & 2.025 & 2.399 & 1 & -0.399 & -0.025 \\
0.5 & 0.9 & 1.958 & 2.294 & 1 & -0.294 & 0.042 \\
\hline
\end{tabular}

It is evident from Table 1 that the optimal hedge ratio is closer to unity (i.e., a full hedge) either when the firm is more risk averse (i.e., a higher $\gamma$ ) or when the bias is more severe (i.e., a higher $\sigma$ ). These two observations match well with intuition. However, the relationship between the optimal hedge ratio and the correlation structure is highly non-monotonic. To see why this is so, suppose that $\beta$ is negative. It follows from Proposition 2 that two opposing incentives are in action. The risk minimization incentive induces the firm to under hedge so as to reduce the volatility of its domestic currency income. As evident from eq. (??), the strength of this incentive varies non-linearly with $\beta$. The speculative incentive, on the other hand, induces the firm to sell the foreign currency forward so as to make a speculative profit, which is 
linear in $\beta$. Thus, for $\beta$ very negative or close to zero, the risk minimization incentive dominates the speculative incentive, thereby making the optimal hedge ratio closer to unity. For $\beta$ not too negative, the speculative incentive dominates the risk minimization incentive and thus the optimal hedge ratio moves further away from unity. Parallel intuition applies to the case where $\beta$ is positive.

\section{OPTIMAL PERFECT CROSS-HEDGING}

This section examines the case of perfect cross-hedging in which the multinational firm has assess to the currency forward market between the third and foreign countries as well as the one between the home and third countries. Using eq. (??) and the fact that $\tilde{S}_{02}=\tilde{S}_{01} \tilde{S}_{12}$, the firm's domestic currency income can be written as

$$
\tilde{W}=F_{01} F_{12} X+\left(F_{01}-\tilde{S}_{01}\right)\left(H_{01}-F_{12} H_{12}\right)+\left(F_{01} F_{12}-\tilde{S}_{01} \tilde{S}_{12}\right)\left(H_{12}-X\right) .
$$

If the firm sells forward $H_{12}$ units of the foreign currency in the currency forward market between the third and foreign countries and, at the same time, sells forward $F_{12} H_{12}$ units of the third currency in the currency forward market between the home and third countries, its domestic currency income, eq. (??), becomes

$$
\tilde{W}=\tilde{S}_{01} \tilde{S}_{12} X+\left(F_{01} F_{12}-\tilde{S}_{01} \tilde{S}_{12}\right) H_{12}
$$

Note that eq. (??) would represent the firm's domestic currency income had a currency forward market between the home and foreign countries been present with the forward exchange rate fixed at $F_{01} F_{12}$. Simultaneously transacting in the two available currency forward markets in the way specified above spans a synthetic forward contract for the missing currency forward market between the home and foreign countries. Indeed, if the firm adopts a 'double full hedge' in which $H_{01}=F_{12} H_{12}$ and $H_{12}=X$, it is evident from eq. (??) that the firm can completely eliminate its 
foreign exchange rate risk exposure and thus receives non-random domestic currency income of $F_{01} F_{12} X$.

The first-order conditions for the optimization problem, eq. (??), are given by

$$
\begin{gathered}
\mathrm{E}\left[U^{\prime}\left(\tilde{W}^{*}\right)\left(F_{01}-\tilde{S}_{01}\right)\right]=0, \\
\mathrm{E}\left[U^{\prime}\left(\tilde{W}^{*}\right) \tilde{S}_{01}\left(F_{12}-\tilde{S}_{12}\right)\right]=0,
\end{gathered}
$$

where an asterisk $\left(^{*}\right)$ indicates an optimal level. The second-order conditions satisfy trivially given risk aversion. The two available currency forward markets in the third country are said to be separately unbiased if, and only if, $F_{01}=\mathrm{E}\left(\tilde{S}_{01}\right)$ and $F_{12}=$ $\mathrm{E}\left(\tilde{S}_{12}\right)$. The optimal perfect cross-hedge in the currency forward market between the third and foreign countries is an over hedge, a full hedge, or an under hedge, depending on whether $H_{12}^{*}$ is greater than, equal to, or less than $X$, respectively.

Proposition 4. Suppose that the two available currency forward markets in the third country are separately unbiased. It is optimal for the multinational firm to adopt an over hedge, a full hedge, or an under hedge in the currency forward market between the third and foreign countries, depending on whether $\tilde{S}_{01}$ is negatively correlated to, independent of, or positively correlated to $\tilde{S}_{12}$, respectively.

Proof. See the appendix.

It is of interest to contrast the results of Proposition 4 with those under the case of imperfect cross-hedging. When the currency forward market between the third and foreign countries co-exists with the one between the home and third countries, Proposition 4 implies that the speculative incentive always dominates the risk minimization incentive, irrespective of the firm's degree of risk aversion. To see why this 
is the case, take variance on both sides of eq. (??) to yield

$$
\begin{aligned}
\operatorname{Var}(\tilde{W})= & \left(H_{01}-F_{12} H_{12}\right)^{2} \operatorname{Var}\left(\tilde{S}_{01}\right)+\left(H_{12}-X\right)^{2} \operatorname{Var}\left(\tilde{S}_{01} \tilde{S}_{12}\right) \\
& +2\left(H_{01}-F_{12} H_{12}\right)\left(H_{12}-X\right) \operatorname{Cov}\left(\tilde{S}_{01}, \tilde{S}_{01} \tilde{S}_{12}\right) .
\end{aligned}
$$

Partially differentiating eq. (??) with respect to $H_{12}$ and evaluating at $H_{12}=X$ yields

$$
\begin{aligned}
\left.\frac{\partial \operatorname{Var}(\tilde{W})}{\partial H_{12}}\right|_{H_{12}=X} & =2\left(H_{01}-F_{12} X\right)\left[\operatorname{Cov}\left(\tilde{S}_{01}, \tilde{S}_{01} \tilde{S}_{12}\right)-F_{12} \operatorname{Var}\left(\tilde{S}_{01}\right)\right] \\
& =2\left(H_{01}-F_{12} X\right) \beta \mathrm{E}\left\{\left[\tilde{S}_{2}-\mathrm{E}\left(\tilde{S}_{2}\right)\right]^{2} \tilde{S}_{01} \tilde{S}_{12}\right\}
\end{aligned}
$$

where the second equality follows from eq. (??). Comparing eq. (??) with eq. (??), as long as $H_{01}>0$, the risk minimization incentive which induces the firm to under hedge for $\beta<0$ or over hedge for $\beta>0$ is alleviated as compared to the case of imperfect cross-hedging. This is rather intuitive because the firm, now possessing two hedging instruments, will not rely solely on the currency forward market between the third and foreign countries to reduce its foreign exchange rate risk exposure, thereby resulting in less distortion in its forward position in this market.

If $\tilde{S}_{1}$ and $\tilde{S}_{2}$ are independent, Proposition 4 implies that $H_{12}^{*}=X$ when the two available currency forward markets are separately unbiased. Using this fact and eq. (??), eq. (??) can be written as

$$
\operatorname{Cov}\left\{U^{\prime}\left[F_{01} F_{12} X+\left(F_{01}-\tilde{S}_{01}\right)\left(H_{01}^{*}-F_{12} X\right)\right], \tilde{S}_{01}\right\}=0
$$

Inspection of eq. (??) reveals that $H_{01}^{*}=F_{12} X$, thereby establishing the following proposition.

Proposition 5. Suppose that the two available currency forward markets in the third country are separately unbiased. If $\tilde{S}_{1}$ and $\tilde{S}_{2}$ are independent, it is optimal for the 
multinational firm to adopt a double full hedge against its foreign exchange rate risk exposure.

With a double full hedge, the firm's domestic currency income is non-random, which implies that the optimal perfect cross-hedging strategy results in complete risk sharing. Unlike in the previous section, the full-hedging theorem resumes in the case of perfect cross-hedging in which $\tilde{S}_{1}$ and $\tilde{S}_{2}$ are independent. This is consistent with the findings by Broll and Eckwert (1996) and Broll (1997).

In the general case where $\beta \neq 0$, it follows from Proposition 4 that a double full hedge is never optimal. To characterize the optimal perfect cross-hedge in the currency forward market between the home and third countries, consider first the case in which $\tilde{S}_{01}$ and $\tilde{S}_{12}$ are negatively correlated (i.e., $\beta<0$ ). Define $\bar{S}_{01}$ as the upper bound of support of $\tilde{S}_{01}$.

Proposition 6. Suppose that the two available currency forward markets in the third country are separately unbiased and that $\tilde{S}_{01}$ and $\tilde{S}_{12}$ are negatively correlated. If $U^{\prime \prime \prime} \geq 0$ and $\beta \geq-\alpha / 2 \bar{S}_{01}$, then $H_{01}^{*}<F_{12} H_{12}^{*}$.

Proof. See the appendix.

To see the intuition underlying Proposition 6, partially differentiating eq. (??) with respect to $H_{01}$ and evaluating at $H_{12}=H_{12}^{*}$ and $H_{01}=F_{12} H_{12}^{*}$ yields

$$
\left.\frac{\partial \operatorname{Var}(\tilde{W})}{\partial H_{01}}\right|_{H_{12}=H_{12}^{*}, H_{01}=F_{12} H_{12}^{*}}=2\left(H_{12}^{*}-X\right) \operatorname{Cov}\left(\tilde{S}_{01}, \tilde{S}_{01} \tilde{S}_{12}\right)
$$

which has the same sign as that of $\operatorname{Cov}\left(\tilde{S}_{01}, \tilde{S}_{01} \tilde{S}_{12}\right)$ since $H_{12}^{*}>X$ by Proposition 4. It is evident from eq. (??) that $\operatorname{Cov}\left(\tilde{S}_{2}, \tilde{S}_{01} \tilde{S}_{12}\right)>0$ if $\beta$ is not too negative. In this 
case, the firm has an incentive to under hedge in the currency forward market between the home and third countries (i.e., $H_{01}^{*}<F_{12} H_{12}^{*}$ ) so as to reduce the volatility of its domestic currency income.

If the firm's marginal utility function is convex (i.e., $U^{\prime \prime \prime} \geq 0$ ), the firm is more sensitive to low realizations of its domestic currency income. Using Kimball's (1990, 1993) terminology, the firm is said to be prudent. The prudent firm prefers to avoid the low realizations of its domestic currency income. Inspection of eq. (??) reveals that this can be done by purchasing the third currency forward in the currency forward market between the home and third countries. Thus, this reinforces the firm's incentive to adopt an under hedge in this market.

Finally, consider the case where $\tilde{S}_{01}$ and $\tilde{S}_{12}$ are positively correlated. The proof of the following proposition is analogous to that of Proposition 6 and thus is omitted.

Proposition 7. Suppose that the two available currency forward markets in the third country are separately unbiased and that $\tilde{S}_{01}$ and $\tilde{S}_{12}$ are positively correlated. If $U^{\prime \prime \prime} \leq 0$, then $H_{01}^{*}>F_{12} H_{12}^{*}$.

Since $\operatorname{Cov}\left(\tilde{S}_{01}, \tilde{S}_{01} \tilde{S}_{12}\right)>0$ for $\beta>0$ by eq. (??) and $H_{12}^{*}<X$ by Proposition 4 , eq. (??) implies that the firm has an incentive to adopt an over hedge in the currency forward market between the home and third countries so as to reduce the volatility of its domestic currency income. If the firm's marginal utility function is concave (i.e., $U^{\prime \prime \prime} \leq 0$ ), the firm is more sensitive to high realizations of its domestic currency income, thereby preferring to avoid those realizations. Inspection of eq. (??) reveals that this can be done by selling the third currency forward in the currency forward market between the home and third countries, thereby reinforcing the firm's incentive 
to adopt an over hedge in this market.

\section{CONCLUSIONS}

In the post-Bretton Woods era, foreign exchange rates have been increasingly volatile, making exchange rate risk management a fact of financial life. This paper has studied how a risk-averse multinational firm, confronting a foreign currency cash flow but possessing no direct hedging opportunities, can employ forward contracts on related currencies to reduce its foreign exchange rate risk exposure. The results show that separate unbiasedness of currency forward markets does not necessarily imply a perfect full hedge which eliminates the entire foreign exchange rate risk exposure of the firm. The optimal cross-hedging strategies depend largely on the firm's marginal utility function and on the correlation of the random spot exchange rates.

Cross-hedging is important because it expands the opportunity set of hedging alternatives. Given the fact that currency forward markets are not readily available in LDCs and are just starting to develop in many of the newly industrializing countries of Latin America and Asia-Pacific, it is clear that, for many multinational firms exposed to currencies of these countries, cross-hedging will continue to be a major risk management technique for reduction of their foreign exchange rate risk exposures.

\section{APPENDIX}

\section{Proof of Proposition 2}

Partially differentiating $\mathrm{E}[U(\tilde{W})]$ with respect to $H_{12}$ and evaluating at $H_{12}=X$ yields

$$
\left.\frac{\partial \mathrm{E}[U(\tilde{W})]}{\partial H_{12}}\right|_{H_{12}=X}=-\operatorname{Cov}\left[U^{\prime}\left(\tilde{S}_{01} F_{12} X\right) \tilde{S}_{01}, \mathrm{E}\left(\tilde{S}_{12} \mid \tilde{S}_{01}\right)\right],
$$

since $F_{12}=\mathrm{E}\left(\tilde{S}_{12}\right)$ and $\operatorname{Cov}(\tilde{x}, \tilde{y})=\operatorname{Cov}[\tilde{x}, \mathrm{E}(\tilde{y} \mid \tilde{x})]$ for any two random variables, $\tilde{x}$ 
and $\tilde{y}$. It follows from the linear projection of $\tilde{S}_{12}$ on $\tilde{S}_{01}$ that $\mathrm{E}\left(\tilde{S}_{12} \mid S_{01}\right)=\alpha+\beta S_{01}$. Furthermore,

$$
\begin{aligned}
\frac{\partial U^{\prime}\left(S_{01} F_{12} X\right) S_{01}}{\partial S_{01}} & =U^{\prime}\left(S_{01} F_{12} X\right)+S_{01} F_{12} X U^{\prime \prime}\left(S_{01} F_{12} X\right) \\
& =U^{\prime}\left(S_{01} F_{12} X\right)\left[1-R\left(S_{01} F_{12} X\right)\right]
\end{aligned}
$$

which is greater than, equal to, or less than zero, depending on whether $R\left(S_{01} F_{12} X\right)$ is less than, equal to, or greater than unity, respectively. Thus, using eq. (??) and the fact that $\beta<0$, the covariance term in eq. (??) is less than, equal to, or greater than zero, depending on whether $R(W)$ is everywhere less than, equal to, or greater than unity, respectively. The desired results then follow immediately from the concavity of $\mathrm{E}[U(\tilde{W})]$.

\section{Proof of Proposition 4}

Since $F_{01}=\mathrm{E}\left(\tilde{S}_{01}\right)$ and $F_{12}=\mathrm{E}\left(\tilde{S}_{12}\right)$, eq. (??) and eq. (??) can be written as

$$
\begin{gathered}
\operatorname{Cov}\left[U^{\prime}\left(\tilde{W}^{*}\right), \tilde{S}_{01}\right]=0 \\
\operatorname{Cov}\left[U^{\prime}\left(\tilde{W}^{*}\right), \tilde{S}_{01} \tilde{S}_{12}\right]=-\mathrm{E}\left[U^{\prime}\left(\tilde{W}^{*}\right)\right] \operatorname{Cov}\left(\tilde{S}_{01}, \tilde{S}_{12}\right) .
\end{gathered}
$$

Note that

$$
\begin{aligned}
\operatorname{Cov}\left[U^{\prime}\left(\tilde{W}^{*}\right), \tilde{W}^{*}\right]= & -\operatorname{Cov}\left[U^{\prime}\left(\tilde{W}^{*}\right), \tilde{S}_{01}\right]\left(H_{01}^{*}-F_{12} H_{12}^{*}\right) \\
& -\operatorname{Cov}\left[U^{\prime}\left(\tilde{W}^{*}\right), \tilde{S}_{01} \tilde{S}_{12}\right]\left(H_{12}^{*}-X\right) \\
= & \mathrm{E}\left[U^{\prime}\left(\tilde{W}^{*}\right)\right] \operatorname{Cov}\left(\tilde{S}_{01}, \tilde{S}_{12}\right)\left(H_{12}^{*}-X\right),
\end{aligned}
$$

where the first equality follows from eq. (??), and the second equality follows from eq. (??) and eq. (??). Since $\operatorname{Cov}\left[U^{\prime}\left(\tilde{W}^{*}\right), \tilde{W}^{*}\right]<0$ given risk aversion, it follows from eq. (??) that the sign of $H_{12}^{*}-X$ must be opposite to that of $\operatorname{Cov}\left(\tilde{S}_{01}, \tilde{S}_{12}\right)$. The desired results then follow.

\section{Proof of Proposition 6}

Since $F_{01}=\mathrm{E}\left(\tilde{S}_{01}\right)$, partially differentiating $\mathrm{E}[U(\tilde{W})]$ with respect to $H_{01}$ and evaluating at $H_{12}=H_{12}^{*}$ and $H_{01}=F_{12} H_{12}^{*}$ yields

$$
\left.\frac{\partial \mathrm{E}[U(\tilde{W})]}{\partial H_{01}}\right|_{H_{12}=H_{12}^{*}, H_{01}=F_{12} H_{12}^{*}}=-\operatorname{Cov}\left\{\mathrm{E}\left[U^{\prime}\left(\tilde{W}^{0}\right) \mid \tilde{S}_{01}\right], \tilde{S}_{01}\right\},
$$


where $\tilde{W}^{0}=F_{01} F_{12} X+\left(F_{01} F_{12}-\tilde{S}_{01} \tilde{S}_{12}\right)\left(H_{12}^{*}-X\right)$. Note that

$$
\begin{aligned}
\frac{\partial \mathrm{E}\left[U^{\prime}\left(\tilde{W}^{0}\right) \mid S_{01}\right]}{\partial S_{01}}= & -\left\{\mathrm{E}\left[U^{\prime \prime}\left(\tilde{W}^{0}\right) \mid S_{01}\right]\left(\alpha+2 \beta S_{01}\right)\right. \\
& \left.+\operatorname{Cov}\left[U^{\prime \prime}\left(\tilde{W}^{0}\right), \tilde{\epsilon} \mid S_{01}\right]\right\}\left(H_{12}^{*}-X\right) .
\end{aligned}
$$

For $\beta \geq-\alpha / 2 \bar{S}_{01}$, the first term in the curly brackets of eq. (??) must be non-positive for all possible realizations of $\tilde{S}_{01}$. Note also that

$$
\frac{\partial U^{\prime \prime}\left(W^{0}\right)}{\partial \epsilon}=-U^{\prime \prime \prime}\left(W^{0}\right) S_{01}\left(H_{12}^{*}-X\right)
$$

which is non-positive since $U^{\prime \prime \prime} \geq 0$ and $H_{12}^{*}>X$ by Proposition 4 . Eq. (??) implies that the second term in the curly brackets of eq. (??) is non-positive for all possible realizations of $\tilde{S}_{01}$. Thus, the right-hand side of eq. (??) must be negative. It then follows from the concavity of $\mathrm{E}[U(\tilde{W})]$ that $H_{01}^{*}<F_{12} H_{12}^{*}$.

\section{BIBLIOGRAPHY}

Anderson, R.W., and Danthine, J.-P. (1981): "Cross Hedging," Journal of Political Economy, 89: 1182-1196.

Arrow, K.J. (1965): Aspects of the Theory of Risk-Bearings. Helsinki: Yrjo Jahnsson Saatio.

Benninga, S., Eldor, R., and Zilcha, I. (1985): "Optimal International Hedging and Output Policies in Commodity and Currency Forward Markets," Journal of International Money and Finance, 4:537-552.

Bohenstedt, G.W., and Goldberger, A.S. (1969): "On the Exact Covariance of Products of Random Variables," American Statistical Association Journal, 64:14391442 .

Broll, U. (1997): "Cross Hedging in Currency Forward Markets: A Note," Journal of Futures Markets, 17:475-482.

Broll, U., and Eckwert, B. (1996): "Cross-Hedging of Exchange-Rate Risk," Review of International Economics, 4:282-286.

Broll, U., Wong, K.P., and Zilcha, I. (1998): "Multiple Currencies and Hedging," Economica, Forthcoming.

Chow, K.W., and Wong, K.P. (1998): "Further Sufficient Conditions for an Inverse Relationship between Productivity and Employment," Quarterly Review of Economics and Finance, Forthcoming. 
Eaker, M.R., and Grant, D.M. (1987): "Cross-Hedging Foreign Currency Risk," Journal of International Money and Finance, 6:85-105.

Eeckhoudt, L., and Gollier, C. (1995): Risk: Evaluation, Management and Sharing. New York: Harvester Wheatsheaf.

Eiteman, D.K., Stonehill, A.I., and Moffett, M.H. (1998): Multinational Business Finance. Massachusetts: Addison-Wesley Publishing Company.

Froot, K.A., Scharfstein, D.S., and Stein, J.C. (1993): "Risk Management: Coordinating Corporate Investment and Financing Policies," Journal of Finance, 48:1629-1658.

Jacque, L.L. (1996): Management and Control of Foreign Exchange Risk. Boston: Kluwer Academic Publishers.

Katz, E., and Paroush, J. (1979): "The Effect of Forward Markets on Exporting Firms," Economics Letters, 4:272-274.

Kawai, M., and Zilcha, I. (1986): "International Trade with Forward-Futures Markets Under Exchange Rate and Price Uncertainty," Journal of International Economics, 20:83-98.

Kerkvliet, J., and Moffett, M.H. (1991): "The Hedging of an Uncertain Future Foreign Currency Cash Flow," Journal of Financial and Quantitative Analysis, 26:565579 .

Kimball, M.S. (1990): "Precautionary Saving in the Small and in the Large," Econometrica, 58:53-73.

Kimball, M.S. (1993): “Standard Risk Aversion," Econometrica, 61:589-611.

Meess, R. (1990): "Currency Fluctuations in the Post-Bretton Woods Era," Journal of Economic Perspectives, 4:117-134.

Powers, M.J., and Castellino, M.G. (1991): Inside the Financial Futures Markets (3rd ed.). New York: Wiley \& Sons.

Pratt, J.W. (1964): "Risk Aversion in the Small and in the Large," Econometrica, $32: 122-136$.

Rawls, S.W., and Smithson, C.W. (1990): "Strategic Risk Management," Journal of Applied Corporate Finance, 1:6-18.

Sercu, P., and Uppal, R. (1995): International Financial Markets and the Firm. Cincinnati: South-Western College Publishing. 


\section{Volkswirtschaftliche Reihe/Economic Series}

Prof. Dr. Hermann ALBECK

Prof. Dr. Jürgen EICHBERGER

Prof. Dr. Ralph FRIEDMANN

Prof. Dr. Robert HOLZMANN

PD Dr. Udo BROLL

Prof. Dr. Christian KEUSCHNIGG

Prof. Dr. Dr. h.c. Rudolf RICHTER Nationalökonomie, insbesondere Wirtschaftstheorie http://www.uni-sb.de/rewi/fb2/eichberger/richter/home-eng.htm
Nationalökonomie, insbesondere Wirtschaftspolitik http://www.uni-sb.de/rewi/fb2/schmidtchen/

Statistik und Ökonometrie http://www.uni-sb.de/rewi/fb2/steinmetz/
9901 Christian KEUSCHNIGG

Finanzwissenschaft

9902 Jürgen EICHBERGER

David KELSEY

Economic Theory

9903 Jürgen EICHBERGER

David KELSEY

Economic Theory

9904 Christian KEUSCHNIGG Wilhelm KOHLER

Finanzwissenschaft

9905 Aymo BRUNETTI
Rationalization and Specialization in Start-up Investment

Non-Additive Beliefs and Strategic Equilibria

Education Signalling and Uncertainty

Eastern Enlargement of the EU:

How Much is it Worth for Austria?

More Open Economies Have Better Governments

Beatrice WEDER Internationale Wirtschaftsbeziehungen 
9906 Ralph FRIEDMANN

Markus GLASER

Statistik und Ökonometrie

9907 Rudolf RICHTER

Economic Theory

9908 Rudolf RICHTER

Economic Theory

9909 Udo BROLL

Kit Pong WONG

International Economics

9910 Udo BROLL

Kit Pong WONG

International Economics
Effects Of The Order Of Entry On Market Share, Trial Penetration, And Repeat Purchases: Empirical Evidence Or Statistical Artefact ?

A Note on the Transformation of Economic Systems

European Monetary Union: Initial Situation, Alter natives, Prospects - -in the Light of Modern Institutional Economics

Capital structure, and the firm under uncertainty

Hedging with Mismatched Currencies 